\title{
Otolith shape analysis as a tool for stock discrimination of the black scabbardfish, Aphanopus carbo Lowe, 1839 (Pisces: Trichiuridae), in Portuguese waters
}

\author{
INÊS FARIAS ${ }^{1}$, ANA RITA VIEIRA ${ }^{2}$, LEONEL SERRANO GORDO ${ }^{2}$ \\ and IVONE FIGUEIREDO ${ }^{1}$ \\ ${ }^{1}$ Unidade de Recursos Marinhos e Sustentabilidade, INRB, L-IPIMAR, Av. Brasília, 1449-006 Lisboa, Portugal. \\ E-mail: ifarias@ipimar.pt \\ ${ }^{2}$ Departamento de Biologia Animal and Centro de Oceanografia, Faculdade de Ciências da Universidade de Lisboa, \\ Bloco C2, Campo Grande, 1749-016 Lisboa, Portugal.
}

\begin{abstract}
SUMMARY: The variability in otolith contour shape of black scabbardfish (Aphanopus carbo) from Portuguese waters was analysed for stock discrimination purposes. The contour shape of otoliths from specimens caught off mainland Portugal, Madeira and Azores archipelagos was digitised and extracted according to the closed-form Fourier analysis technique. Mainland and Madeira specimens were compared through the adjustment of a MANOVA model to the normalised elliptic Fourier descriptor (NEFDs) obtained for the otoliths of 200 females and 200 males sampled at each area. Significant differences were found between areas and between sexes; the interaction term was not statistically significant. The effect of the area also proved to be significant when samples from the three regions were considered. These results were further supported by the discriminant analysis of the individual NEFDs for which the correct classifications were $87.5-89 \%$ when they were considered by sex and total length for the mainland and Madeira, and 90.9-97.7\%, when NEFDs from the three areas were compared by sex and fish length. Otolith contour shape was shown to be a possible tool for differentiating between black scabbardfish stocks in the NE Atlantic.
\end{abstract}

Keywords: black scabbardfish, otolith, contour, shape, Fourier descriptors.

RESUMEN: ANÁLISIS DE LA FORMA DEL OTOLITO COMO UNA HERRAMIENTA PARA LA SEGREGACIÓN DE STOCKS DE SABLE NEGRO, Aphanopus CARBo LOWE, I839, EN AguAS PORTUGUESAS. - Se analizó la variabilidad de forma del contorno de otolitos del sable negro (Aphanopus carbo) procedentes de aguas Portuguesas como posible herramienta por la gestión de stocks. La imagen del contorno de otolitos de ejemplares capturados frente a la costa portuguesa, Archipiélago de Madeira y Archipiélago de Azores fue digitalizada y extraída conforme la técnica de análisis de Fourier para contornos cerrados. Como primer paso se compararon ejemplares de la costa portuguesa y de Madeira a través de un MANOVA sobre los descriptores elípticos de Fourier normalizados (NEFDs) estimados para los otolitos de 200 hembras y 200 machos de cada localidad. Se observaron diferencias significativas entre áreas y entre sexos, pero no hubo interacción entre los dos factores. El efecto del área también resultó ser significativo cuando se consideraron las muestras de las tres regiones. Estos resultados fueron corroborados por el análisis discriminante de los NEFDs para los cuales el porcentaje de clasificaciones correctas estuvo comprendido entre 87.5 y $89 \%$ cuando se compararon los NEFDs de la costa portuguesa y de Madeira por sexo, y considerando la talla del pez; y entre 90.9 y $97.7 \%$ cuando se consideraron las tres áreas por sexo y la talla total. Se demostró que la forma del contorno del otolito es una posible herramienta para diferenciar grupos de sable negro.

Palabras clave: sable negro, otolito, contorno, forma, descriptores de Fourier.

\section{INTRODUCTION}

The black scabbardfish, Aphanopus carbo Lowe, 1839 , is a deep-water species from the fam- ily Trichiuridae that is common at depths between 450 and $1300 \mathrm{~m}$ and has a world-wide distribution. There are records of the species in the NW and NE Atlantic, from Iceland to the south of Madeira Island 
(Anon., 1984; Gordon, 1986; Merrett et al., 1991); southern Indian Ocean (Piotrovskii, 1979) and NW Pacific (Clarke and Wagner, 1976). Specifically, in the northeast Atlantic it is one of the leading deepwater species exploited. As a consequence, knowledge of its demographic structure and dynamics in the distribution area is crucial for a suitable assessment and management of the stock(s).

In Portugal it was the fifth most important fish species in terms of commercial landings in 2007, attaining almost 6.5 thousand tonnes (INE, 2008). The main Portuguese ports where this species is landed are Sesimbra (in mainland Portugal) and several ports in the Madeira archipelago. In the Azores archipelago the species is exploited on an irregular basis.

In previous studies it was shown that the black scabbardfish has differences in size range and sexual cycle along the NE Atlantic. In general, specimens caught off Madeira and the Canary Islands attain larger total length and cover all maturity stages (Figueiredo et al., 2003; Pajuelo et al., 2008; Neves et al., 2009). Specimens caught in Portuguese continental waters are predominantly immature or spent, although there have been occasional records of prespawning individuals, with total lengths varying between 60 and $130 \mathrm{~cm}$, whereas in NW Scotland the specimens are small (bellow $65 \mathrm{~cm}$ total length) and are all immature. Furthermore, there are no records of occurrence of black scabbardfish juveniles smaller than $60 \mathrm{~cm}$, except for two specimens with 10 and $15 \mathrm{~cm}$ length that were found in the stomach of an Alepisaurus ferox Lowe, 1833, captured off Madeira (Maul, 1954).

The extended distribution area of black scabbardfish along the NE Atlantic together with incomplete knowledge on the stock structure and dynamics of the species led the following questions to be raised: Is there more than one stock distributed in Portuguese waters? More specifically, do specimens caught off mainland Portugal, Madeira and the Azores come from distinct stocks?

Studies using fish otoliths through characterisation of chemical composition, measurements on spacing between rings, morphometry and contour shape are up-to-date techniques contributing significant information to stock identification (Bird et al., 1986; Castonguay et al., 1991; Lombarte and Castellón, 1991; Campana and Casselman, 1993; Friedland and Reddin, 1994; Bolles and Beg, 2000; Torres et al., 2000; Cardinale et al., 2004; Stransky et al., 2008). Campana and Casselman (1993) considered the analysis of otolith shape to be an easily determined measure of stock identity since it is speciesspecific and barely variable with growth. Furthermore, methods based on otoliths are more reliable than the ones that use external morphometric traits because they are not affected by short-term variations in fish physiological condition or by standard tissue preservation techniques, and their appearance and shape often vary geographically (Campana and Casselman, 1993; Ponton, 2006).

The main objective of this work was to try answering the questions posed above by comparing the otolith contour shape of specimens caught off the Portuguese mainland, Madeira and the Azores, and by quantifying the differentiation among them.

\section{MATERIAL AND METHODS}

\section{Sampling}

Black scabbardfish specimens were sampled from commercial landings of longliners operating off mainland Portugal (Sesimbra, 38 $26^{\prime}{ }^{\prime} 9^{\circ} 06^{\prime} \mathrm{W}$ ), the Madeira archipelago, and the Azores archipelago. A map of the northeast Atlantic showing the areas where samples of black scabbardfish were collected is presented in Figure 1.

The collection of otoliths was carried out at the same time periods in all areas from 2000 to 2001 and from 2004 to 2007. Left sagitta otoliths from specimens with 1000 to $1300 \mathrm{~mm}$ total length were randomly selected. For the same time period and fish length range, the total number of otoliths available from the Azores was significantly lower than the number available from the other two locations because in the former area the fishery of this species is merely exploratory. To guarantee a balanced number of observations in each comparative analysis, the following strategies were adopted:

- 200 otoliths per sex from mainland Portugal and Madeira were randomly selected;

- 44 otoliths per sex from mainland Portugal, Madeira and the Azores were randomly selected.

\section{Image and shape analysis}

Otolith digital images were captured using a SONY ${ }^{\circledR}$ DFW-SX910 digital camera linked to an Olympus ${ }^{\circledR}$ SZX9 stereomicroscope and the Noesis ${ }^{\circledR}$ TNPC 4.1 image analysis software. Each otolith was 


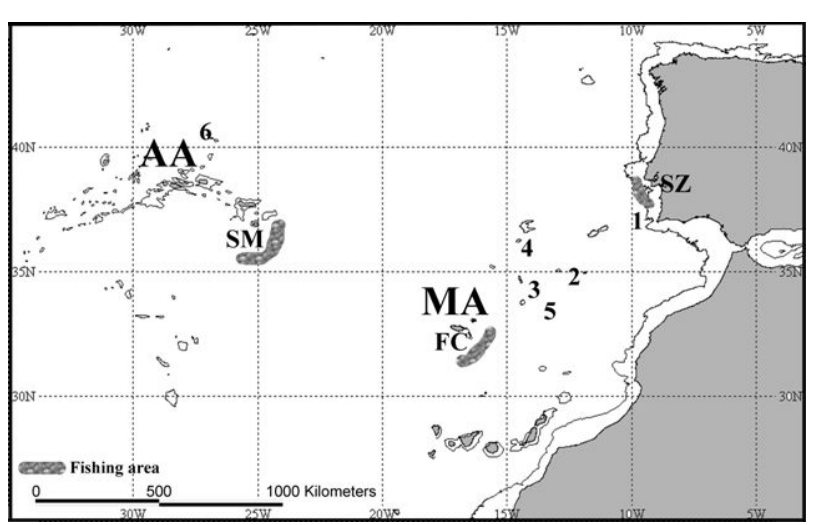

FIG. 1. - Map of the southern Northeast Atlantic with the sampling locations of black scabbardfish. AA, Azores Archipelago; FC, Funchal; MA, Madeira Archipelago; SM, Santa Maria Island; SZ, Sesimbra (mainland Portugal); 1, Gorringe seamount; 2, Ampère seamount; 3, Unicorn bank; 4, Lion seamount; 5, Seine seamount; 6 , Sedlo seamount.

previously immersed in a 1:1 solution of glycerinealcohol, positioned with the sulcus acusticus facing down and the rostrum to the left, and photographed under reflected light (Fig. 2).

A closed-form Fourier analysis (Younker and Ehrlich, 1977; Kuhl and Giardina, 1982; Lestrel, 1997) was applied to the two-dimensional projection of the distal side of the otolith. This method decomposes the irregular shape of the contour into a series of orthogonal terms - the elliptic Fourier descriptors (EFDs) or harmonics. The harmonics are a series of sine and cosine curves that are generated by taking a Fourier expansion of radius vectors drawn from the centroid of the object as a function of the phase angle, resulting in a series of sine and cosine curves (Younker and Ehrlich, 1977; Bird et al., 1986).

The SHAPE program developed by Iwata and Ukai (2002) was used to extract the contour shape of the otoliths and to evaluate biological contour shapes based on the EFDs. The programs included in SHAPE can be used on image processing (namely contour recording and derivation of EFDs), on principal component analysis (PCA) of EFDs, and

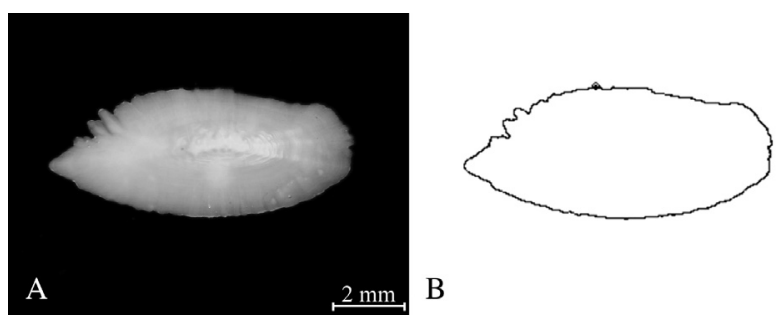

FIG. 2. - Otolith of black scabbardfish: (A) distal side and (B) extracted contour. This otolith is from a female with $1079 \mathrm{~mm}$ total length and an estimated age of 8 years, caught off mainland Portugal. on the visualisation of shape variations estimated by the principal components. The ChainCoder $1.2 \mathrm{a}$ package extracts the contour of an object from its digital image and stores the relevant information as chain-codes. Next, the Chc2Nef package provides the normalised EFD coefficients (NEFDs) through a discrete Fourier transformation of the chain-coded contour. The EFD coefficients are automatically normalised in relation to the first harmonic (represented by an offset circle and with almost no information on the contour shape), and consequently they become invariant to size, rotation and starting point (Kuhl and Giardina, 1982; Iwata and Ukai, 2002).

As suggested by Stransky et al. (2008), the level of $99 \%$ accumulated variance was adopted to select the minimum number of harmonics according to the period, which is assembled by plotting the percentage of accumulated variance explained by the $n$th harmonic vs the harmonic number, $n$.

\section{Multivariate statistical analysis}

The effect of area and sex on the NEFDs was tested by multivariate analysis of variance (MANOVA). MANOVA is a generalised form of analysis of variance that is performed simultaneously on several (correlated) dependent variables that cannot simply be combined. Fish size (total length) was assigned to size classes and included in the analyses to account for the differences in length distribution between groups. Based on the growth rate estimated for black scabbardfish within the considered size range, fish size was discretised into classes of $35 \mathrm{~mm}$. Otolith shape differences were analysed through the adjustment of a MANOVA (with Pillai's trace test of significance) using area and sex (both conditioned to fish length) as the independent variables and the NEFDs as the dependent variables.

\section{Discriminant analysis}

Discriminant analysis (DA) has two main objectives in the separation of groups: description of the differences between two or more groups, and prediction of the group in which a sampling unit is included (Rencher, 1995). DA for more than two groups is also commonly used as a follow-up to MANOVA. The basic principal of DA is that groups of specimens can be divided according to functions that are linear combinations of the classifying variables (in this case, the NEFDs). Within the various DA approaches, a flexible discriminant analysis (FDA) was 
employed. The FDA recasts the linear DA limitations as a linear regression problem by replacing linear regression by a non-parametric regression, implicitly enlarging the basis of the vector space (Hastie et al., 1997). The FDA model was built based on a matrix with the observed NEFDs and fish length to evaluate the differences between geographical areas. Sexes were analysed separately.

\section{RESULTS}

\section{Image and shape analysis}

From the observation of a collection of otoliths, the contour shape of black scabbardfish otoliths proved to be highly variable, hampering the definition of an average shape attributable to each area. Tuset et al. (2008) have described the black scabbardfish otolith as follows: elliptic to oblong shape, with ventral margin sinuate to crenate; the sulcus acusticus is heterosulcoid, ostial, and median; the ostium is funnel-like and shorter than the cauda, which is tubular, straight, and ending half way to the posterior margin; the anterior region is peaked; the rostrum is short, broad, and pointed; the antirostrum is absent or short, narrow, and pointed; the excisura is wide with or without a deep, acute notch; and the posterior region is round.

The analysis of periodograms, for which an example is presented in Figure 3, showed that a maximum of 20 harmonics (excluding the Oth harmonic) was needed to explain $99 \%$ of otolith shape variation. Since the normalisation of the NEFDs causes the degeneration of the first three coefficients to fixed values $\left(a_{1}=1\right.$ and $b_{1}=c_{1}=0$ ) (Tracey et al., 2006), each individual was represented by the subsequent 77 coefficients.

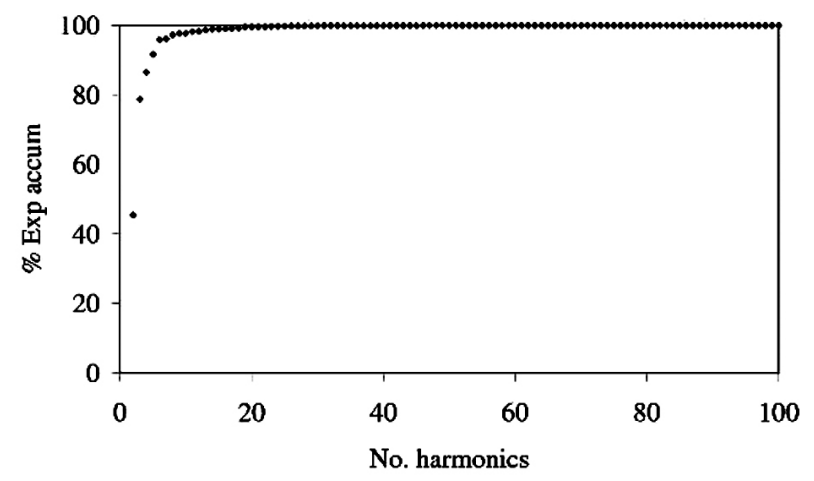

FIG. 3. - Periodogram estimated for a randomly selected otolith. \% Exp accum is the accumulated percentage of variance explained by the $n$th harmonic.
TABLE 1. - Summary of MANOVA $(\mathrm{n}=800)$ on otolith NEFDs from the mainland and Madeira. Df, degrees of freedom; Pillai, Pillai's test statistics; approx F, approximation of F statistics; num $\mathrm{Df}$, numerator degrees of freedom; den Df, nominator degrees of freedom; $\operatorname{Pr}(>\mathrm{F})$, p-value.

\begin{tabular}{lcccccc}
\hline & Df & Pillai & approx F & num Df & den Df & $\operatorname{Pr}(>\mathrm{F})$ \\
\hline Area & 1 & 0.374 & 5.362 & 77 & 690 & $<2 \mathrm{e}-16^{*}$ \\
Sex & 1 & 0.132 & 1.364 & 77 & 690 & $0.026^{*}$ \\
Area: Sex & 1 & 0.110 & 1.108 & 77 & 690 & 0.255 \\
Area: Sex: & & & & & & \\
Fish length & 30 & 3.022 & 1.046 & 2310 & 21570 & 0.071 \\
Residuals & 766 & & & & & \\
\hline
\end{tabular}

$* \operatorname{Pr}(>\mathrm{F})<0.05$

TABLE 2. - Summary of MANOVA $(\mathrm{n}=264)$ on otolith NEFDs from the mainland, Madeira and the Azores. Df, degrees of freedom; Pillai, Pillai's test statistics; approx F, approximation of F statistics; num Df, numerator degrees of freedom; den Df, nominator degrees of freedom; $\operatorname{Pr}(>\mathrm{F})$, p-value.

\begin{tabular}{|c|c|c|c|c|c|c|}
\hline & Df & Pillai & approx $\mathrm{F}$ & num Df & den Df & f $\quad \operatorname{Pr}(>F)$ \\
\hline Area & 2 & 1.053 & 2.154 & 154 & 298 & $8.617 \mathrm{e}-09 *$ \\
\hline Sex & 1 & 0.362 & 1.090 & 77 & 148 & 0.324 \\
\hline Area: Sex & 2 & 0.727 & 1.104 & 154 & 298 & 0.23 \\
\hline $\begin{array}{l}\text { Area: Sex: } \\
\text { Fish length } \\
\text { Residuals }\end{array}$ & $\begin{array}{c}34 \\
224\end{array}$ & 9.991 & 0.978 & 2618 & 6154 & 0.747 \\
\hline
\end{tabular}

$* \operatorname{Pr}(>\mathrm{F})<0.05$

\section{Multivariate statistical analysis}

The result from the adjustment of the MANOVA model to otolith NEFDs from the mainland and Madeira $(n=200$ females and 200 males from the mainland +200 females and 200 males from Madeira) showed a significant effect of area and sex on otolith contour shape differences, but no significant interaction between the factors, at a confidence level of 0.05 (Table 1).

With the adjustment of a MANOVA to compare otolith NEFDs from the three areas (mainland, Madeira and the Azores; $n=44$ females and 44 males from the Azores +44 females and 44 females from the mainland +44 females and 44 males from Madeira), the differences found between areas were statistically significant for any usual confidence level (Table 2). In this analysis, sexes were not significantly different and no interaction was found between the two factors.

\section{Discriminant analysis}

Since the effect of sex on the otoliths' contour shape was shown to be significant for the set of data 
TABLE 3. - Classification success (\%) of flexible discriminant analysis adjusted to samples from Madeira and mainland Portugal, for each sex separately and assuming fish length and NEFDs as descriptive variables. Percentages given in rows represent the classification into areas given in columns. Values in bold represent the correct classifications. Misclassification error is 0.12 for females and males.

\begin{tabular}{lcccc}
\hline & \multicolumn{2}{c}{ Females } & \multicolumn{2}{c}{ Males } \\
& Madeira & Mainland & Madeira & Mainland \\
& & & & \\
\hline \multirow{2}{*}{ Madeira } & $\mathbf{8 8 . 0}$ & 12.5 & $\mathbf{8 9 . 0}$ & 12.0 \\
Mainland & 12.0 & $\mathbf{8 7 . 5}$ & 11.0 & $\mathbf{8 8 . 0}$ \\
\hline
\end{tabular}

TABLE 4. - Classification success (\%) of flexible discriminant analysis adjusted to samples from the Azores, Madeira and mainland Portugal, for each sex separately and assuming total length and NEFDs as descriptive variables. Percentages given in rows represent the classification into areas given in columns. Values in bold represent the correct classifications. Misclassification error is 0.08 for females and 0.04 for males.

\begin{tabular}{lcccccc}
\hline & \multicolumn{3}{c}{$\begin{array}{c}\text { Females } \\
\end{array}$} & \multicolumn{4}{c}{$\begin{array}{c}\text { Males } \\
\text { Azores Madeira Mainland }\end{array}$} & Azores \\
& & & & & & \\
\hline Azores & $\mathbf{9 0 . 9}$ & 0.0 & 2.3 & $\mathbf{9 5 . 5}$ & 2.3 & 2.3 \\
Madeira & 0.0 & $\mathbf{9 5 . 5}$ & 6.8 & 2.3 & $\mathbf{9 5 . 5}$ & 0.0 \\
Mainland & 9.1 & 4.5 & $\mathbf{9 0 . 9}$ & 2.3 & 2.3 & $\mathbf{9 7 . 7}$ \\
\hline
\end{tabular}

from the mainland and Madeira, the FDA was performed for each sex separately, including fish length as a descriptive variable. The FDA ran between mainland Portugal and Madeira showed a relatively high classification success for each area (Table 3). For Madeira specimens, $88.8 \%$ of females and $89.0 \%$ of males were classified in the proper group. For samples from mainland Portugal, the proportions were lower: $87.5 \%$ for females and $88.0 \%$ for males. The associated misclassification error was 0.12 for both analyses. The first discriminant function explained $100 \%$ of between-group variance in both cases.

For the comparison between the three areas (the Azores, Madeira and the mainland), the classification success was much higher than in the previous analyses (Table 4). The highest values were found for males from the mainland $(97.7 \%)$, followed by females and males from Madeira and males from the Azores (all 95.5\%), and females from the Azores and the mainland (both 90.9\%). The associated misclassification error was approximately 0.08 for females and 0.04 for males. The score plots for the first two discriminant functions (Figs. 4 and 5) showed a distinct separation between the three areas. The first and second discriminant functions explained $64.85 \%$ and $100 \%$ (females), and $61.86 \%$ and $100.00 \%$ (males) of between-group variance, respectively.

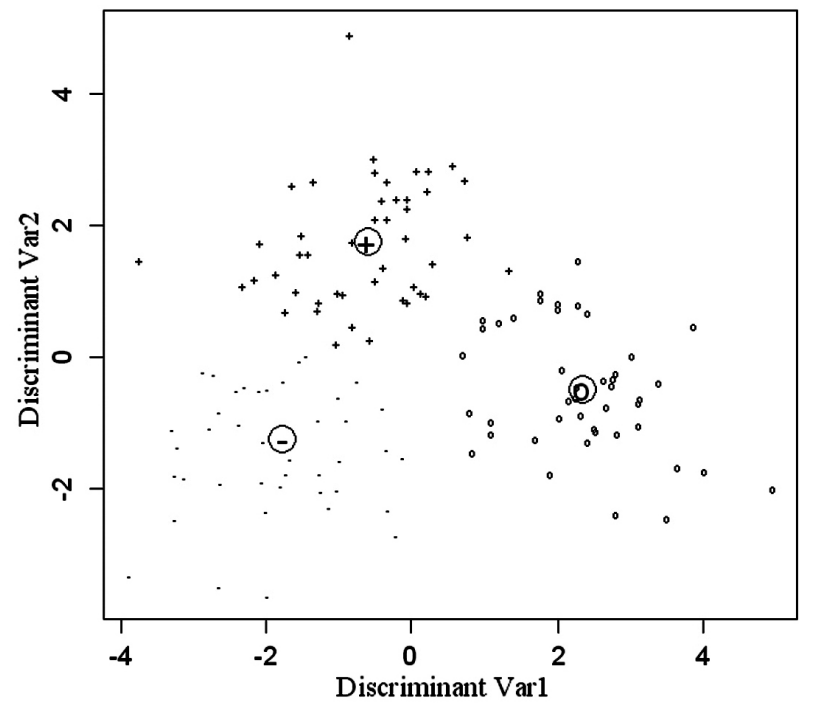

Fig. 4. - Discriminant analysis function scores for female samples from the Azores (-), Madeira (o) and mainland Portugal (+), based on Fourier normalised descriptors of the first 20 harmonics. The numbered circles indicate the class centroids.

\section{DISCUSSION}

Fourier analysis is considered to be the most objective and powerful shape-analysis technique for capturing the entire shape variation and small-scale individual differences in the otolith outline (Campana and Casselman, 1993), although its biological interpretation is more complex than that of linear morphometrics (Stransky and MacLellan, 2005).

In this study, only otoliths from fish with a total length between 1000 and $1300 \mathrm{~mm}$ were used

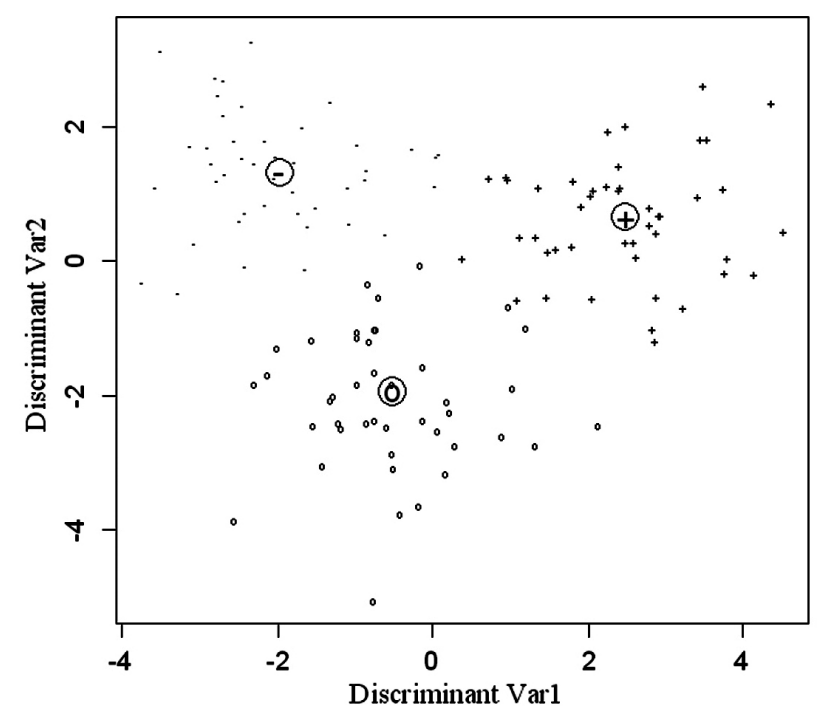

FIG. 5. - Discriminant analysis function scores for male samples from the Azores (-), Madeira (o) and mainland Portugal (+), based on Fourier normalised descriptors of the first 20 harmonics. The numbered circles indicate the class centroids. 
to guarantee that the specimens were restricted to the adult stage and hence to avoid the confounding effect of allometric growth on otolith shape (Cardinale et al., 2004). Bird et al. (1986) and Lombarte and Castellón (1991) observed that otolith contour shape becomes rougher with increasing age and after maturation in herring and in species of the genus Merluccius, respectively. However, Cardinale et al. (2004) demonstrated that NEFDs are size-independent variables. Based on specimens collected for the project in which the present study is included, the length at first maturity was estimated to be 1078 $\mathrm{mm}$ for females and $1062 \mathrm{~mm}$ for males (Neves et $a l ., 2009)$. Although variations in otolith shape with size and maturation have not been proved for black scabbardfish, the chosen range guarantees that most of the specimens are mature adults. Moreover, fish length was included in the analysis to account for the effect of sampling different fish sizes.

The first MANOVA showed that the otolith contour shape of specimens caught off the Madeira archipelago is different from that of specimens caught off mainland Portugal, suggesting the probable occurrence of more than one distinct stock in Portuguese waters. Sex also had a significant effect on otolith contour shape. The high classification success and the associated low misclassification error related to this analysis corroborate the MANOVA results.

Significant differences were also found when the three locations were considered simultaneously, and in this case the classification success percentages were even higher and the misclassification errors much lower. The highest percentages of misclassification referred to female otoliths from the mainland classified in the Azores group and vice-versa. This could indicate that some specimens from these two locations are subject to similar environmental pressure or even share genetic traits, since these are the main driving factors influencing the otolith shape. However, it is important to note that the results from the analyses that considered the three areas are less consistent than those for two areas because the number of otoliths used was relatively small.

Recently, Stefanni and Knutsen (2007) identified two distinct phylogroups within the genus Aphanopus from complete sequences of the control region and partial sequences of cytochrome $b$ in mtDNA. One group included the sequences from Madeira, mainland Portugal and the Faraday seamount, whereas all the sequences from the southern coast of Pico Island
(Azores) were clustered together in another group. The remaining sampling locations had sequences represented in both groups. Based on these results, these authors suggest that the sequences from Pico correspond to A. intermedius (Parin, 1983). To avoid the bias that would result from including A. intermedius in the present analyses, specimens from Azores were morphologically analysed to assure that only $A$. carbo were used.

Other possible sources of misclassification in otolith shape analysis are imprecision in the methodology, individual variability and migration (Campana and Casselman, 1993; Tracey et al., 2006). Cardinale et al. (2004) have shown that, even under the same temperature and growing conditions, different stocks of cod have significantly different otolith shapes. This observation seems to indicate that, aside from environmental conditions that determine variations related to growth, genetic dissimilarities can also influence the otolith shape (Galley et al., 2006). In fact, genetic, microchemical or tagging discrimination techniques have proved to be very accurate in stock separation (Tracey et al., 2006). Nonetheless, otolith contour shape analysis has the advantage of being cheaper and more time-efficient than either of those practices.

The answer to whether morphometric differences are a necessary and sufficient condition to differentiate stocks depends on the definition of the term stock, and this is usually dependent on the purpose for which stocks are being determined (Cadrin and Friedland, 1999). A straightforward and broad definition would be "a group of fish that maintains itself over time in a definable area" (Booke, 1981), such that groups with different growth or reproductive dynamics should be modelled separately for stock assessment purposes. For stock identification based on morphometrics, the same author defines it as "a group of individuals within a species that maintain common characters that are environmentallydependent". Furthermore, it should be taken into consideration that even if morphological differences may be effective in identifying phenotypic groups, inferring reproductive isolation or its absence from shape or size patterns may be misleading (Cadrin and Friedland, 1999).

According to these results, the otolith contour shape proved to be a suitable tool for the separation of black scabbardfish stocks from Madeira and mainland Portugal. Regarding specimens from the Azores, the only possible conclusion-based on 
the small number of otoliths analysed-is that there seems to be an overlap with specimens from the mainland. The present work also corroborates the importance of assuring certain sampling conditions, namely using a sufficiently large number of otoliths and considering samples within the same total length class and age.

\section{ACKNOWLEDGEMENTS}

We would like to thank Joana Vasconcelos and Valentina Costa for providing otoliths from the Madeira and Azores archipelagos, respectively, Hiroyoshi Iwata for kindly providing the protocol to obtain the $\mathrm{x}-\mathrm{y}$ coordinates from the chain-code data, and Maria Magalhães for providing the map of the NE Atlantic. This study was partially supported by Fundação para a Ciência e Tecnologia (project POCTI/CVT/46851/2002).

\section{REFERENCES}

Anon. - 1984. INIP - Programa de apoio às pescas na Madeira - III. Cruzeiro de reconhecimento de Pesca e Oceanografia 020330981. Relatórios INIP, 22.

Bird, J.L., D.T. Eppler and D.M. Checkley. - 1986. Comparisons of herring otoliths using Fourier-series shape-analysis. Can. J. Fish. Aquat. Sci., 43: 1228-1234.

Bolles, K.L. and G.A. Berg. - 2000. Distinction between silver hake (Merluccius bilinearis) stocks in U.S. waters of the northwest Atlantic based on whole otoliths morphometrics. Fish. Bull., 98: 451-462.

Booke, H.E. - 1981. The conundrum of the stock concept - Are nature and nurture definable in fishery science? Can. J. Fish. Aquat. Sci., 38: 1479-1480.

Cadrin, S.X. and K.D. Friedland. - 1999. The utility of image processing techniques for morphometric analysis and stock identification. Fish. Res., 43: 129-139.

Campana S.E. and J.M. Casselman. - 1993. Stock discrimination using otolith shape analysis. Can. J. Fish. Aquat. Sci., 50: 10621083.

Cardinale, M., P. Doering-Arjes, M. Kastowsky and H. Mosegaard. - 2004. Effects of sex, stock, and environment on the shape of known-age Atlantic cod (Gadus morhua) otoliths. Can. J. Fish. Aquat. Sci., 61(2):158-167.

Castonguay, M., P. Simard and P. Gagnon. - 1991. Usefulness of Fourier analysis of otolith shape for Atlantic mackerel (Scomber scombrus) stock discrimination. Can. J. Fish. Aquat. Sci., 48: 296-302.

Clarke, T.A. and P.J. Wagner. - 1976. Vertical distribution and other aspects of the ecology of certain mesopelagic fishes taken near Hawaii. Fish. Bull., 74: 635-645.

Figueiredo, I., P. Bordalo-Machado, S. Reis, D. Sena-Carvalho, T. Blasdale, A. Newton and L.S. Gordo. - 2003. Observations on the reproductive cycle of the black scabbardfish (Aphanopus carbo Lowe, 1839) in the NE Atlantic. ICES J. Mar. Sci., 60: 774-779.

Friedland, K.D. and D.G. Reddin. - 1994. Use of otolith morphology in stock discriminations of Atlantic salmon (Salmo salar). Can. J. Fish. Aquat. Sci., 51: 91-98.

Galley, E.A., P.J. Wright and F.M. Gibb. - 2006. Combined meth- ods of otolith shape analysis improve identification of spawning areas in Atlantic cod. ICES J. Mar. Sci., 63: 1710-1717.

Gordon, J.D.M. - 1986. The fish populations of the Rockall Trough. Proceedings of the Royal Society of Edinburgh, 88B: 191-204.

Hastie, T., R. Tibshirani and A. Buja. - 1997. Flexible discriminant and mixture models. In: J. Kay and D. Titterington (eds.), Proceedings of "Neural Networks and Statistics" conference, Edinburgh, 1995. Oxford University Press, Oxford, U.K.

INE. - 2008. Estatísticas da Pesca 2007. Instituto Nacional de Estatística, I.P., Lisboa, Portugal.

Iwata, H. and Y. Ukai. - 2002. SHAPE: A computer program package for quantitative evaluation of biological shapes based on elliptic Fourier descriptors. J. Hered., 93: 384-385.

Kuhl, F.P. and C.R. Giardina. - 1982. Elliptic Fourier features of closed contour. Comp. Graph. Image Process. 18: 236-258.

Lestrel, P.E. - 1997. Introduction and overview of Fourier descriptors. In: P.E. Lestrel (ed.), Fourier Descriptors and Their Application in Biology, pp. 22-44. Cambridge University Press, Cambridge, U.K.

Lombarte, A. and A. Castellón. - 1991. Interespecific and intraespecific otolith variability in the genus Merluccius as determined by image analysis. Can. J. Zool., 69: 2442-2449.

Maul, G.E. - 1954. Notes and exhibitions. [A sketch of Madeiran Ichthyology with observations on the ecology of the most important fishes]. Proc. Zool. Soc. Lond., 123: 901-903.

Merrett, N.R., J.D.M. Gordon, M. Stehmann and R.L. Haedrich. 1991. Deep demersal fish assemblage structure in the Porcupine Seabight (eastern North Atlantic): slope sampling by three different trawls compared. J. Mar. Biol. Assoc. U.K., 71: 329-358.

Neves, A., A.R. Vieira, I. Farias, I. Figueiredo, V. Sequeira and L.S. Gordo. - 2009. Reproductive strategies in black scabbardfish (Aphanopus carbo Lowe, 1839) from NE Atlantic. Sci. Mar., 73S2: 19-31.

Pajuelo, J.G., J.A. González, J.I Santana, J.M. Lorenzo, A. GarcíaMederos and V. Tuset. - 2008. Biological parameters of the bathyal fish black scabbardfish (Aphanopus carbo Lowe, 1839) off the Canary Islands, Central-east Atlantic. Fish. Res., 92(23): $140-147$

Piotrovskii, A.S. - 1979. On the distribution of the black scabbardfish Aphanopus carbo (family Trichiuridae) in the Indian Ocean. J. Ichthyol., 19(5): 145-146.

Ponton, D. - 2006. Is geometric morphometrics efficient for comparing otolith shape of different fish species? J. Morph., 267: 750-757.

Rencher, A.C. - 2002. Discriminant analysis: Description of group separation. In: A.C. Rencher (ed.). Methods of Multivariate Analysis, pp. 270-298. John Wiley and Sons, New York, U.S.A.

Stefanni, S. and H. Knutsen. - 2007. Phylogeography and demographic history of the deep-sea fish Aphanopus carbo (Lowe, 1839 ) in the NE Atlantic: vicariance followed by secondary contact or speciation? Mol. Phyl. Evol., 42: 38-46.

Stransky, C. and S. E. MacLellan. - 2005. Species separation and zoogeography of redfish and rockfish (genus Sebastes) by otolith shape analysis. Can. J. Fish. Aquat. Sci., 62: 2265-2276.

Stransky, C., A.G. Murta, J. Schlickeisen and C. Zimmermann. 2008. Otolith shape analysis as a tool for stock separation of horse mackerel (Trachurus trachurus) in the Northeast Atlantic and Mediterranean. Fish. Res., 89: 159-166.

Tracey, S.R., J.M. Lyle and G. Duhamel. - 2006. Application of elliptical Fourier analysis of otolith form as a tool for stock identification. Fish. Res., 77: 138-147.

Torres, G.J., A. Lombarte and B. Morales-Nin. - 2000. Sagittal otolith size and shape variability to identify geographical intraspecific differences in three species of genus Merluccius. $J$. Mar. Biol. Ass. U.K., 80: 333-342.

Tuset, V.M., A. Lombarte and C.A. Assis. - 2008. Otolith atlas for the western Mediterranean, north and central eastern Atlantic. Sci. Mar., 72S1: 7-198.

Younker, J.L. and R. Ehrlich. - 1977. Fourier biometrics: harmonic amplitudes as multivariate shape descriptors. Syst. Zool., 26: 336-342.

Scient. ed.: J. Lleonart.

Received December 12, 2008. Accepted September 8, 2009.

Published online December 22, 2009. 